Denise Alvarez ${ }^{1}$

Marcelo Figueiredo ${ }^{1}$

Lucia Rotenberg ${ }^{2}$

\section{Aspectos do regime de embarque, turnos e gestão do trabalho em plataformas offshore da Bacia de Campos (RJ) e sua relação com a saúde e a segurança dos trabalhadores*}

\author{
Scheduling, shifts, and work management in offshore platforms \\ of Campos Basin (Rio de Janeiro) and their relationship with \\ workers' safety and health
}

\begin{abstract}
${ }^{1}$ Professores coordenadores do Núcleo de Estudos em Inovação, Conhecimento e Trabalho (NEICT) - Programa de Engenharia de Produção da Universidade Federal Fluminense (UFF), Rio de Janeiro, RJ.

${ }^{2}$ Pesquisadora do Laboratório de Educação em Ambiente e Saúde, Instituto Oswaldo Cruz (Fiocruz), Rio de Janeiro, RJ.

*Este trabalho foi subsidiado pelo Conselho Nacional de Desenvolvimento Científico e Tecnológico (CNPq), através do Programa Institucional de Bolsas de Iniciação Cientifica (PIBIC), e pela Coordenação de Aperfeiçoamento de Pessoal de Nível Superior (Capes), através do Pós-doutorado sênior processo no BEX 1817/09-4.
\end{abstract}

Contato:

Denise Alvarez

Rua Passo da Pátria, 156, bloco D, sala 306 - São Domingos - Niterói/RJ

CEP: 24210-240

E-mail:

alvarez.dena@gmail.com

\section{Resumo}

O artigo aborda pesquisa desenvolvida na indústria petrolífera offshore da Bacia de Campos (Rio de Janeiro, Brasil), campo empírico que acompanhamos de forma sistemática desde 2003 e que se situa no rol dos sistemas sociotécnicos complexos. Nosso objetivo é destacar os riscos potenciais associados à organização do trabalho, em especial o regime de embarque e o sistema de turnos adotados nas plataformas de petróleo por algumas das empresas atuantes na região. Isto porque entendemos que, no contexto investigado, os problemas relacionados à saúde - aí inclusos os que se situam na esfera mental - e à segurança dos trabalhadores possuem relação importante com aspectos da organização do trabalho, como aqueles que aqui se encontram em foco. Indicam-se proposições de mudança com o intuito de reduzir os impactos deletérios de tais fatores sobre a saúde e a segurança dos trabalhadores. A base teóricometodológica utilizada na pesquisa se fundamenta, principalmente, no instrumental da Ergonomia da Atividade e da Psicodinâmica do Trabalho, numa perspectiva ergológica.

Palavras-chave: organização do trabalho; regime de embarque; trabalho em turnos; saúde mental e segurança; indústria petrolífera offshore.

\begin{abstract}
This paper focuses on a research about offshore oil industry in the Campos Basin (Rio de Janeiro, Brazil), an empirical field we have followed up systematically since 2003, which can be classified as a complex socio-technical system. Our aim is to highlight the potential risks associated with work organization, mainly the schedule and shift systems adopted by some of the companies on oil platforms. We understand that in the investigated context, problems related to workers' safety and health - including mental health - are related to aspects of work organization, as those we have focused in this paper. We propose changes that may reduce the deleterious impact of those factors on workers' safety and health. The theoretical and methodological framework used in the research is based mainly on Ergonomics of Activity and Psychodynamics of Work, from an ergological perspective.
\end{abstract}

Keywords: work organization; schedule; shift work; mental health and safety; offshore oil industry. 


\section{Introdução}

Nosso interesse pelo estudo do trabalho na indústria petrolífera offshore 4 na Bacia de Campos (RJ) deve-se em especial aos índices de acidentes em âmbito nacional envolvendo as empresas do setor e suas contratadas. Os episódios ocorridos nos últimos anos demonstram que os investimentos crescentes nas áreas de Segurança, Meio Ambiente e Saúde (SMS) são insuficientes e/ou inadequados para lidar com os inúmeros e graves fatores de risco presentes no processo. Esse quadro ganhou maior visibilidade internacional após o acidente com a plataforma P-36, no começo de 2001 (SIQUEIRA; NEUROHR, 2005), e com o adernamento da plataforma P-34, ao final de 2002. Esses eventos e os que os precederam podem ser vistos como o ápice de um processo que denota uma substancial e perigosa defasagem entre a gestão da inovação tecnológica e a gestão do risco (FIGUEIREDO; ALVAREZ, 2007). No ano de 2001, 4 mortes já haviam sido registradas na Bacia de Campos (RJ) antes do acidente com a P-36. O quadro era preocupante não apenas no norte fluminense, mas também em outros locais do país, com dois grandes vazamentos de óleo em 2000 - na baía de Guanabara (RJ) e no Rio Iguaçu (PR) - e um outro vazamento em 2001, no terminal de Alemoa (SP) (LUCENA, 2004). Em verdade, se retrocedermos um pouco mais no tempo, verificamos também um número elevado de mortes nos anos 1990 na Bacia de Campos (FIGUEIREDO, 2001; FREITAS et al., 2001).

O Gráfico 1 a seguir nos mostra, além dos indicadores elevados de óbitos no final dos anos 1990, a predominância de mortes acometendo trabalhadores terceirizados na comparação com os efetivos, e isto em todo o período retratado, com a única exceção de 2001, ano do acidente com a plataforma P-36, no qual 11 brigadistas (efetivos da Petrobras) perderam a vida. ${ }^{5}$

E se recuarmos ainda mais no tempo, iremos nos deparar com a ocorrência de dois acidentes ampliados nos anos 1980, ambos envolvendo a plataforma Central de Enchova (PCE-1), sendo que no primeiro deles (em 1984) faleceram 37 trabalhadores; no segundo (em 1988) não houve mortes, mas a unidade ficou completamente destruída pelo incêndio.

Por sinal, os acidentes de Enchova (PCE-1) e da P-36 nos fazem lembrar a severidade do contexto com o qual lidamos se considerarmos que estamos no campo da possibilidade de ocorrência de acidentes industriais ampliados, com graves danos para os trabalhadores, para o meio ambiente e para as instalações, dadas as características que cercam o funcionamento deste processo produtivo. Essa constatação também nos permite afirmar que tais acidentes demandariam maior atenção por parte dos interessados nessa temática, tal como aqueles descritos na literatura científica (LEPLAT; TERSSAC, 1990; DROGARIS, 1993; PERROW, 1999; LLORY, 1999; FREITAS; SOUZA; MACHADO, 2000). Destacamos ainda que as características da organização do trabalho do setor offshore tenderiam a elevar a exposição dos trabalhadores aos riscos associados às possíveis ocorrências de acidentes, visto que o custo psíquico (cognitivo, afetivo) demandado pelas atividades é potencializado pelo regime de embarque ${ }^{6}$ e pelo sistema de turnos.

Apesar da gravidade do contexto exposto, o número de artigos nacionais de cunho acadêmico tendo como foco a questão da saúde e segurança no setor de exploração e produção petrolífera offshore é reduzido, como

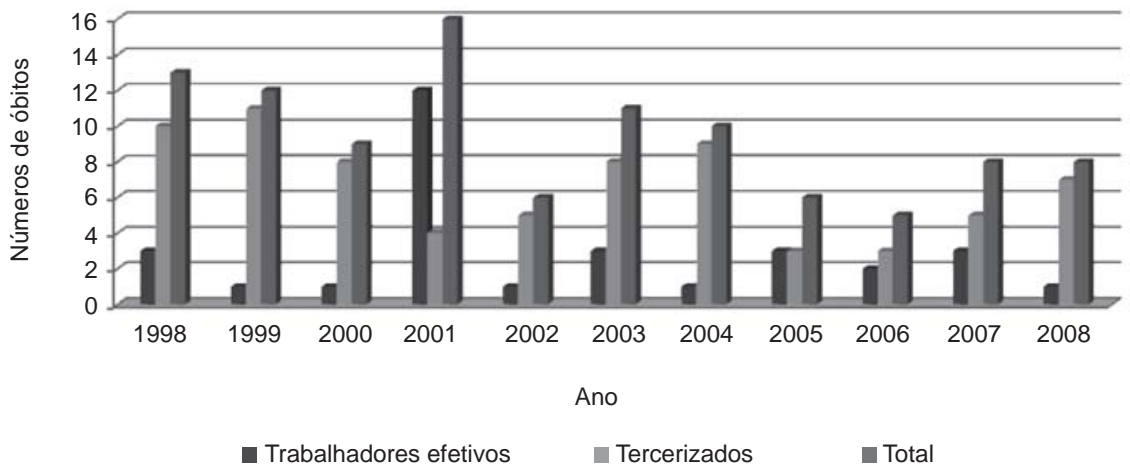

Gráfico 1 Mortes de trabalhadores na indústria petrolífera offshore da Bacia de Campos entre os anos de 1998 e 2008

Fonte: Dados obtidos junto ao Sindicato dos Petroleiros do Norte Fluminense com base nas Comunicações de Acidentes de Trabalho (CATs) fatais.

\footnotetext{
${ }^{4}$ Designação dada às atividades de exploração e produção de petróleo em alto mar.

${ }^{5}$ A tendência a um patamar menor de óbitos, a partir de 2002, indica como o acidente da P-36 obrigou a empresa a envidar esforços no campo da saúde e segurança para tentar reverter a tendência de então. Uma análise mais detalhada a este respeito pode ser encontrada em Figueiredo et al. (2008).

${ }^{6}$ Conforme veremos adiante, regime no qual os trabalhadores permanecem de modo ininterrupto nas plataformas - ou seja, sem retorno à terra, mesmo após o término de sua jornada diária de trabalho - ao longo de 14 dias (normalmente o período de duração de um embarque), após os quais se dá o desembarque (retorno à terra).
} 
comentam Souza e Freitas (2002), tomando como parâmetro a base de busca Scielo (Bireme). Dentre os estudos a este respeito incluem-se o de Freitas et al. (2001) e Leite (2006), que abordam, respectivamente, os acidentes de trabalho e o confinamento em plataformas na Bacia de Campos. A estes estudos, acrescentam-se alguns publicados em língua inglesa, identificados a partir do sistema de busca Pubmed, que enfocam a privação do sono em petroleiros da Bacia de Campos (FISCHER et al., 2000), suas percepções sobre o trabalho em turnos (RODRIGUES; FISCHER; BRITO, 2001) e os efeitos nefastos da terceirização do setor à saúde e segurança dos trabalhadores (FIGUEIREDO et al. 2008).

Tendo em mente esse quadro, o objetivo deste texto é analisar a questão dos riscos potenciais à saúde - incluindo aí problemas de ordem mental - e à segurança associados à organização do trabalho, com destaque para o regime de embarque e o sistema de turnos. Insere-se como parte de um esforço mais geral de análise dos resultados do projeto de pesquisa "Trabalho, saúde e segurança na indústria petrolífera offshore na Bacia de Campos (RJ)”, desenvolvido por nosso núcleo em parceria com o Sindicato dos Petroleiros do Norte Fluminense (Sindipetro-NF). O referencial teórico-metodológico que norteia o projeto em curso privilegia a Ergonomia da Atividade (DANIELLOU, 2004; WISNER, 1994) e a Psicodinâmica do Trabalho (DEJOURS, 1993, 2008). Neste artigo, incorporamos autores não estritamente vinculados a estes campos, buscando um encaminhamento sinérgico entre saberes das ciências e da experiência prática pertinentes à análise de situações de trabalho, na linha do que propõe a perspectiva ergológica (SCHWARTZ, 2000; SCHWARTZ; DURRIVE, 2007). Além de contribuir para a produção de conhecimento sobre uma área relativamente pouco estudada em nosso país, o presente estudo constitui uma oportunidade de incorporar a visão dos petroleiros - a partir do diálogo com os pesquisadores - nas discussões sobre o trabalho em turnos e o regime de embarque em plataformas offshore no que concerne às suas possíveis relações com a saúde física e mental e com a segurança no trabalho.

\section{Caracterização do regime offshore e do trabalho em turnos com ênfase na indústria petrolífera no Brasil}

Antes de abordar a caracterização do regime offshore e do trabalho em turnos no contexto investigado, cabe ressaltar que esta se insere numa discussão mais ampla acerca das temporalidades no trabalho. Autores como Alaluf (2000) e Quéinnec (2007) afirmam que, a partir dos anos 1990, há uma tendência crescente à diversi- ficação dos tempos de trabalho, inseparável daquela mais geral das formas de emprego.

No plano referente à organização do trabalho, Quéinnec (2007) diz ser o horário um dos mais importantes componentes da dimensão temporal da atividade e da sua organização. O autor identifica então duas visões relacionadas a tempo e trabalho: a primeira, tecnocêntrica, insuficiente para explicar o conjunto de problemas subjacentes ao horário, baseia-se na ideia newtoniana da medida universal física e "objetiva” do tempo na qual todas as unidades de intervalo são iguais. Esse tempo apóia-se na definição comum de uma norma que estabelece a duração (anual ou semanal) do trabalho e das pausas (de descanso ou de férias) postulando ainda, implicitamente, uma estabilidade do funcionamento humano, sejam quais forem as horas e as durações do trabalho. A outra visão é antropocêntrica e traz para a discussão o ponto de vista das ciências humanas e sociais, particularmente da Ergonomia. Segundo ele, essa visão apresentaria quatro componentes do tempo profissional.

O primeiro componente refere-se ao tempo dentro do trabalho, que diz respeito às exigências temporais das tarefas (duração, velocidade, disposição, programação...) e está ligado à dinâmica dos processos técnicos que dita a distribuição e o ritmo da atividade. $\mathrm{O}$ segundo, denominado tempo de trabalho, concerne ao contrato de trabalho, à definição das durações e dos horários da atividade profissional construídos desde meados do século XIX em torno de normas, como a duração semanal, a duração diária ou o(s) dia(s) de descanso (consecutivos ou não) e as férias. O terceiro seria o tempo do trabalho, que vai delimitar a distribuição de espaços do trabalho e de não-trabalho: é o uso do tempo. Confronta a temporalidade profissional e a temporalidade sociofamiliar da vida fora do trabalho. O último seria o tempo no trabalho e diz respeito às características temporais do funcionamento humano (velocidade de execução, tempo de reação, ritmos biológicos, aquisição de experiências, desgaste profissional, envelhecimento biológico).

Por conseguinte, falar sobre a relação tempo e trabalho obriga-nos ao uso da noção de tempo no plural, pois os seus componentes dentro do, de, do e no trabalho colocam os trabalhadores em situações conflituosas, que requerem a mobilização de adequações e estratégias para atender às solicitações do processo de produção em foco. Conflitos que devem ser percebidos na atividade e nas construções de saúde do corpo-si, ${ }^{7}$ ou corpo-pessoa, e que abarcam tanto o plano físico, como o psíquico e o social. Feita esta ressalva teórica, vejamos na sequência algumas das principais características e problemas correlatos ligados ao trabalho em turnos no regime offshore.

\footnotetext{
${ }^{7}$ Segundo Durrive e Schwartz (2008), o trabalho não existe sem alguém que trabalha e é difícil nomear este sujeito, porque isso subentenderia que ele se encontraria bem delimitado, definido. Entretanto, se a atividade é efetivamente conduzida por alguém em carne e osso, ela tem prolongamentos que ultrapassam a pessoa física e que são solicitados, incorporados e inscritos no corpo: o social, o psíquico, o institucional, as normas e os valores (do contexto e aqueles retrabalhados), a relação com as instalações, os produtos, os tempos, os homens, os níveis de racionalidade etc. Este alguém que trabalha - este centro de arbitragens que governa a atividade - pode assim ser designado corpo-si ou corpo-pessoa (DURRIVE; SCHWARTZ, 2008).
} 
No cenário nacional, o estudo desenvolvido por Sampaio, Borsoi e Ruiz (1998), no contexto cearense, avalia que, genericamente, as condições de vida e de trabalho nas plataformas são consideradas "perversas" ou "de sacrifício", pois quase toda a extensão das plataformas configura-se em área de risco. Disso resulta que até tarefas cotidianas simples devem se pautar por procedimentos que envolvam certa rigidez de conduta.

Além disso, Sampaio, Borsoi e Ruiz (1998) apontam que o regime de embarque desorganiza a vida social ao exacerbar a dicotomia ambiente de trabalho/ambiente doméstico. Como durante o embarque o trabalho offshore se desenrola em 2 turnos de revezamento ao longo das 24 horas diárias, não se pode menosprezar as possíveis consequências do trabalho noturno, as quais também se manifestam como marcas de desgaste físico e mental - "as marcas da vida entre os trabalhadores" (WISNER, 1994, p. 21). Estas, muitas vezes, não se apresentam como doenças e, sim, como fatores predisponentes ao agravamento de doenças, isto é, maior suscetibilidade aos agentes nocivos, ao cansaço, ao sofrimento mental, ao envelhecimento precoce, entre outros (FISCHER; MORENO; ROTENBERG, 2003). Ressalte-se ainda que, especialmente na indústria petroquímica, os trabalhadores em turnos relatam maiores exposições aos riscos e às condições ambientais desfavoráveis, tais como frio, chuva, vento, escuridão etc. (FISCHER; PARAGUAY; BRUNI, 1998) e, dependendo do local, estas podem se tornar extremamente adversas, como nos casos do Mar do Norte e da costa canadense. No que tange ao estudo de instalações offshore no Mar do Norte, Gardner (2003) aponta o perigo potencial da não conexão entre doenças ocupacionais e trabalho, na medida em que elas, não raro, aparecem muito tempo depois da exposição e os gerentes tendem a não se envolver em sua investigação da mesma maneira como o fazem nos casos de acidentes típicos.

Um aspecto essencial a se considerar no trabalho offshore é que, finda a jornada, os trabalhadores têm que permanecer na instalação em que atuam, o que significa se restringir, geralmente por duas semanas, à plataforma no que se refere às atividades de lazer e sono além de, necessariamente, vivenciar a interface casatrabalho de forma diferenciada de outros trabalhadores. Outra questão relevante são as jornadas longas - de 12 horas -, o que destoa do padrão usualmente observado em outros esquemas industriais, em que raramente se observam jornadas de 12 horas por períodos superiores a uma semana (PARKES, 2007).

Observamos, portanto, que o trabalho em regime offshore implica algumas especificidades importantes em relação aos tempos e aos espaços de trabalho. Em função destas peculiaridades, os modelos teóricos desenvolvidos para representar os riscos de longas jornadas e do trabalho em turnos à saúde e segurança não se aplicam diretamente ao trabalho contínuo em localidades offshore, como comenta Parkes (2007) em revisão sobre o tema. A este respeito, cabe considerar a observação de Ross (2009), segundo a qual a comunidade de trabalhadores offshore vivencia uma situação que precisa ser avaliada de forma específica, ao invés de ser tratada como uma extensão direta do trabalho em turnos realizado onshore. Desta forma, para subsidiar a discussão proposta no presente artigo, descrevemos na parte final deste item alguns problemas concernentes ao trabalho realizado em regime offshore.

Apresentamos a seguir as principais características do trabalho em turnos e as bases legais brasileiras sobre esse esquema de trabalho, de forma a analisar o tipo de regime usualmente praticado na Bacia de Campos, implantado a partir de negociações entre representantes dos trabalhadores e das empresas envolvidas.

O trabalho em turnos relaciona-se com a continuidade da produção e a quebra da continuidade do trabalho realizado pelo trabalhador (MORRICE, 1985). Os sistemas de turnos podem ser classificados como: (i) fixos, quando o trabalho ocorre sempre nos mesmos horários, como, por exemplo, os plantões em hospitais, que se dão em horários fixos - diurnos ou noturnos; (ii) irregulares, quando há variações nos horários de início e fim da jornada, como ocorre frequentemente nos setores de transportes aéreo e rodoviário; e (iii) alternantes ou em rodízio, quando há alternância regular dos horários de trabalho segundo uma escala predeterminada, como é o caso dos trabalhadores de plataformas de petróleo offshore, em sua maioria (FISCHER; MORENO; ROTENBERG, 2003).

O estudo de Rodrigues (2001), que tem como foco plataformas do tipo unidades de perfuração marítimas (UPMs) no Brasil, elenca pelo menos três fatores que impõem o trabalho em turnos: razões de ordem econômica, logística e características do processo. Além disso, segundo ele, há o próprio interesse dos trabalhadores que preferem se submeter às jornadas estendidas e às longas permanências a bordo do que às viagens diárias de helicópteros, o que, por sua vez, também seria inviável em termos logísticos.

Vale ressaltar que, no que se refere aos turnos e às jornadas de trabalho, a Constituição Brasileira de 1988 (artigo $7^{\circ}$, inciso XIV) previu a jornada de seis horas para o trabalho realizado em turnos ininterruptos de revezamento, salvo negociação coletiva. Em empresas que possuem três turnos contínuos, ou seja, turnos contínuos durante as 24 horas do dia, 7 dias por semana, a $5^{\underline{a}}$ turma de trabalhadores foi criada com o objetivo de seguir a recomendação prevista na Constituição. A jurisprudência firmada após a aprovação da nova Constituição estabeleceu, porém, que apenas nas empresas em que há modificação dos horários dos trabalhadores seria exigida a redução das jornadas de trabalho. ${ }^{8}$

\footnotetext{
${ }^{8}$ Cabe ressaltar que se tratou de uma interpretação equivocada do termo "revezamento", como sinônimo de alternância de horários de trabalho (ou seja, turnos alternantes), quando, com efeito, o termo refere-se a sucessivas turmas que se alternam. Por isso, a jornada mais curta não deveria se restringir aos trabalhadores em turnos alternantes, mas sim se aplicar inclusive aos trabalhadores em turnos fixos (FISCHER; MORENO; ROTENBERG, 2003).
} 
O trabalho offshore caracteriza-se como em turnos alternantes, pois normalmente, dos 14 dias embarcados, os funcionários passam 7 dias no turno da noite e os outros 7 no turno do dia, revezando-se continuamente, o que qualifica este regime de trabalho como turno ininterrupto de revezamento. Na Bacia de Campos, após a Constituição de 1988, o sindicato dos petroleiros negociou para os funcionários efetivos, por intermédio de acordo coletivo, jornadas de 12 horas durante 14 dias, desembarque no $15^{\circ}$ e mais 20 dias de folga, exigindo que a empresa introduzisse uma $5^{\underline{a}}$ turma para viabilizar as escalas do então novo arranjo. Este esquema é conhecido como 14/21, o que corresponde a 14 dias de trabalho seguidos de 21 dias de folga. À época, o sindicato, com base em pesquisa de opinião junto aos trabalhadores, apresentou as três alternativas desejadas pelos trabalhadores em ordem de prioridade: 7 x 14, 10 x 20 e 14 x 28. Argumentava-se que o regime preferido pelos petroleiros deveria limitar o período de embarque a 10 dias, pois predominava a avaliação de que, após o $10^{\mathrm{o}}$ dia de embarque, com o desgaste, a tendência era que se deteriorassem as relações interpessoais a bordo (PESSANHA, 1994; RODRIGUES, 2001). No entanto, sabe-se que a redução do período de embarque exige a mobilização de um contingente maior de trabalhadores e intensifica o tráfego aéreo, elevando os custos de produção, o que encaminhou as negociações para o estabelecimento do regime de 14 x 21. Em 2008, a categoria logrou o reconhecimento de parte do $15^{\mathrm{o}}$ (o dia de desembarque) como dia trabalhado, seguindo a tendência de países como a Itália, em que o dia ("sem trabalho") imediatamente posterior a uma sequência de dias de trabalho noturno não é considerado descanso. Isto porque se considera que neste dia - chamado de smonto notte (ao pé da letra, desmonte da noite) - o trabalhador está se recuperando do cansaço acumulado (WEDDERBURN, 1997). No setor em estudo, além de turnos longos (12 horas) e rodiziantes (a cada 7 dias), tem-se a diferença de tempo de descanso para os terceirizados (14 dias em vez de 21) e o regime de sobreaviso para algumas funções, em que os trabalhadores que as ocupam não são rendidos por outro trabalhador após a jornada de 12 horas, comumente das 7 horas às 19 horas, a qual pode se estender por conta de demandas vinculadas à sua atividade. Pela mesma razão, também podem ser convocados a qualquer momento, mesmo que dentro das suas 12 horas de descanso. Para isto, basta que sua presença na área seja indispensável ou que haja necessidade premente de contatá-lo para dirimir alguma dúvida ou tomar-se alguma decisão que não possam ser assumidas por outro profissional em dada ocasião. Tais profissionais recebem $12 \%$ de adicional.

Ainda no campo legal, verifica-se que a legislação brasileira, com o Decreto 3.048, de 06/05/1999, representa um avanço no que diz respeito à proteção legal conferida aos trabalhadores de turnos rodiziantes. Ela inclui o trabalho em turnos e noturno como fator de risco de natureza ocupacional nos benefícios a serem dados aos trabalhadores em caso de acidente e doenças profissionais, apesar de conhecermos as dificuldades para se estabelecer os nexos causais demandados pela lei. Em que pese tais limitações, os aspectos legais traduzem o reconhecimento social do impacto deste tipo de organização do trabalho à saúde e à vida sociofamiliar dos trabalhadores, com potenciais repercussões na segurança do trabalho, como veremos adiante.

Como dito anteriormente, na Bacia de Campos, os trabalhadores passam 14 dias embarcados. Por isto, no offshore, é muito frequente a alusão à vivência cindida ocasionada pelos "dois mundos", o "mundo de lá" (da plataforma) e o "mundo daqui ou de cá" (da terra) (FIGUEIREDO; ATHAYDE, 2005). Tal vivência se prenuncia antes mesmo do embarque e, pela sua expressiva recorrência junto a essa população, ficou conhecida como "TPE (tensão pré-embarque)", tal como destaca a investigação de Leite (2006), que corresponde à expressão em inglês pre-boarding stress syndrome, cuja intensidade varia do desconforto em algumas famílias à manifestação intensa de sintomas ligados à saúde (RODRIGUES; FISCHER; BRITO, 2001).

Em paralelo aos "dois mundos" dos petroleiros, está a chamada "síndrome do marido intermitente" (intermittent husband syndrome), expressão cunhada por Morrice et al. (1985) para descrever a tríade ansiedade-depressão-dificuldades sexuais observada entre as esposas de trabalhadores de plataformas do Mar do Norte. O termo intermitente traduz a adaptação repetida e mútua demandada pelo retorno do trabalhador a cada duas semanas (ROSS, 2009). Estudo mais recente com esposas de petroleiros revela preocupações que incluem o impacto da ausência do pai aos filhos, a comunicação com o parceiro ausente e aspectos da segurança no trabalho offshore. Como esperado, a ausência do pai também se reflete nas crianças (ROSS, 2009), para as quais os repetidos embarques se traduzem em fonte de sofrimento, em especial se a ausência coincide com eventos importantes, como aniversários (MAUTHNER; MACLEAN; MCKEE, 2000; PARKES; CARNELL; FARMER, 2005).

Na maior parte da Bacia de Campos, como já dissemos, o trabalho se dá em jornadas de 12 horas em turnos alternantes - 7 dias no período diurno e 7 no noturno $(7 \mathrm{D} / 7 \mathrm{~N})$, ou na ordem inversa (7N/7D). Assim, os petroleiros offshore lidam com o sono compulsório no período diurno em pelo menos 7 dos 14 dias embarcados e, quando da troca do turno do dia para o turno da noite, ocorre a chamada "virada", expressão indicativa do rearranjo do ciclo de sono/vigília que esta troca demanda. $\mathrm{O}$ desgaste da primeira semana (jornada de 12 horas com a "virada" ao final) tende a aumentar para uma parcela significativa de trabalhadores que se desloca de outros estados do Brasil (regiões norte e nordeste) até os locais de embarque nos municípios de Campos e Macaé-RJ (FIGUEIREDO; ALVAREZ, 2007).

No Mar do Norte são observados regimes e esquemas que envolvem 2 semanas de trabalho diurno (7h-19h ou 6h-18h) / 2 semanas de trabalho noturno (19h-7h ou 18h-6h) (PARKES, 2007), assim como regimes de duas semanas de embarque semelhantes aos adotados no Brasil. 
Pesquisas realizadas por Parkes (2007) com petroleiros que trabalham no regime $7 \mathrm{D} / 7 \mathrm{~N}$ mostram alterações importantes na duração e na qualidade do sono logo após a mudança do dia para a noite. As medidas do nível de alerta (através de questionários) mostram um decréscimo importante nas duas primeiras noites, que apresentam melhora no início das noites subsequentes, porém permanecem baixos no fim de todas as noites de trabalho.

O regime inverso, ou seja, 7N/7D, é o preferido pelos trabalhadores, em função de sentirem seu sono totalmente ajustado à rotina diurna ao saírem da plataforma, como se referem os petroleiros tanto de Campos (RODRIGUES; FISCHER; BRITO, 2001), como do Mar do Norte (PARKES, 2007). Todavia, cabe ressaltar que nem sempre a preferência dos trabalhadores recai sobre o que seria esperado a partir dos resultados de pesquisas. Mesmo quando se leva em conta todo o conhecimento sobre os impactos das escalas de trabalho com base na cronobiologia, isso não garante que os trabalhadores estejam mais satisfeitos, podendo, em alguns casos, até preferirem situações consideradas mais restritivas do ponto de vista dos horários (VERDIER; BARTHE; QUÉINNEC, 2003). Na realidade, eles buscam conciliar as diferentes dimensões da sua saúde com as restrições impostas pela natureza de seu trabalho e as demandas da vida em geral.

\section{Considerações metodológicas}

Os aportes metodológicos operacionalizados no presente estudo contribuem para uma maior aproximação do trabalho real, assim como do real do trabalho ${ }^{9}$ e, por conseguinte, da defasagem entre as dimensões da prescrição e do efetivamente realizado. Isto se dá por intermédio de métodos indiretos, via participação dos trabalhadores nas discussões, ao se valorizar sua experiência acumulada ao longo dos anos, seu saberfazer, seus atributos associados àquela parcela de conhecimento que emerge no curso da atividade. Assim, buscamos mobilizar uma "comunidade ampliada de pesquisa” - CAP (ATHAYDE; BRITO; NEVES, 2003), envolvendo os "pesquisadores diretos" (coordenadores do projeto), o "grupo sindical” (demandante) e um "grupo de trabalhadores diretamente interessados" (contatados via direção sindical), além de um "pesquisador indireto" (via acompanhamento da pesquisa sem participação sistemática no campo). ${ }^{10}$ Tal iniciativa inspira-se nas "comunidades científicas ampliadas" (ODDONE, 1984) e consiste em uma tentativa de avançar em relação à proposta desenvolvida por esse autor. Dessa forma, foi nossa intenção fazer dialogarem (dialeticamente) os saberes investidos na atividade com as competências disciplinares dando visibilidade aos debates de normas e às ressingularizações presentes nas inúmeras situações (SCHWARTZ; DURRIVE, 2007). Para isso, lançamos mão de encontros com os trabalhadores, denominados "encontros sobre o trabalho” (SCHWARTZ; DURRIVE, 2007), que são a fonte principal do material aqui tratado. Entre o final de 2002 e o final de 2004 foram realizados 20 "encontros sobre o trabalho" com a "comunidade ampliada de pesquisa” (ATHAYDE; BRITO; NEVES, 2003) que tiveram duração de cerca de 2 h30 cada um.

No período 2002-2003, os petroleiros participantes (em média 3 por encontro) eram em sua maioria membros da direção sindical pertencentes ao quadro efetivo da Petrobras (com 10 a 25 anos de empresa). No ano de 2004, os petroleiros que compuseram os grupos (de 4 a 6 por encontro) eram em sua maioria de empresas terceirizadas, afastados em função de acidentes ocorridos, com atuação profissional variando entre 5 e 20 anos. Dentre as principais funções ocupadas por eles, vale citar as de sondador, plataformista, torrista, técnico de inspeção, guindasteiro e soldador.

As conversas e os encontros foram registrados em fitas cassete seguindo de forma flexível um roteiro semiestruturado de conversação. Em alguns momentos, lançou-se mão de materiais audiovisuais que serviam para nortear a discussão em torno de um determinado tema pré-selecionado como objeto de debate minucioso, por vezes, abrindo espaço para eleger-se um "terceiro termo" como foco de discussão e contribuindo assim para evocar os constrangimentos e os múltiplos aspectos relacionados à atividade.

O conteúdo presente neste material permitiu-nos acessar aspectos importantes do funcionamento (e disfuncionamento) do sistema técnico e, em âmbito mais global, do processo produtivo, além dos constrangimentos aí presentes. Permitiu-nos também apreender um pouco da vivência subjetiva (hipóteses sobre o porquê e o como da relação vivenciada no trabalho) que vem à tona ao mobilizar-se a capacidade dos trabalhadores de analisarem sua situação, em especial no que tange à percepção do risco (DEJOURS, 2008). As principais questões suscitadas pelos temas debatidos retornavam ao confronto com a literatura acadêmica disponível, sendo possível, desta forma, depararmo-nos com a condição de "desconforto intelectual”, tal como evocada por Schwartz (1995).

Além desses encontros, outros procedimentos relacionados abaixo funcionaram à guisa de "fontes primárias" e deram origem aos materiais analisados.

\footnotetext{
${ }_{9}^{9}$ Segundo Dejours (2008, p. 352), o real do trabalho "se deixa conhecer por sua resistência a se submeter aos conhecimentos e às diferentes formas de saber-fazer".

${ }^{10}$ Parceria com o pesquisador Milton Athayde, do PPGPS/UERJ, em função do pós-doutoramento (2005/2006) de um dos coordenadores do projeto, sob sua orientação.
} 
- Observações: visitas rápidas (de algumas horas) às seguintes plataformas da Petrobras: P-47, Cherne 2, Namorado 1 e Namorado 2; duas visitas a aeroportos (de Macaé e de Campos), acompanhadas da realização de entrevistas abertas com trabalhadores;

- Atividades conjuntas sindicato/universidade: participação dos pesquisadores como observadores em 4 encontros da categoria; participação como expositores e debatedores em 4 congressos da categoria; organização de um seminário de discussão conjunta entre pesquisadores (Universidade Federal Fluminense e Universidade de Provença) e sindicalistas intitulado "Ergonomia, Ergologia e Mundos do Trabalho";

- Dispositivos de conversa (19 entrevistas individuais): realizadas pelos pesquisadores com assessores do sindicato e profissionais da Bacia de Campos dotados de qualificações diversas (engenheiro naval, engenheiro e técnica atuantes na perfuração e perfilação de poços, técnico de lançamento de linha, operador de produção e manutenção, técnico de inspeção, oficial de náutica, médico do trabalho e gerente de recursos humanos da Bacia de Campos). Nove destas entrevistas foram realizadas ao longo do período já mencionado (final de 2002 até final de 2004), e o restante ao longo dos anos de 2006 a 2009.

O material aqui apresentado é oriundo desses diálogos e, por questões óbvias de espaço, foram selecionados apenas alguns poucos trechos dos "encontros sobre o trabalho" com o grupo de empregados efetivos e trechos de duas entrevistas individuais, uma realizada com uma técnica de inspeção e, a outra, com um engenheiro ligado à área de perfuração e perfilação de poços. Tanto os encontros como as duas entrevistas selecionadas ocorreram na fase inicial da pesquisa, compreendida entre os anos de 2002 e 2004.

Vale ressaltar que na escuta dos petroleiros durante os "encontros do trabalho," assim como nas entrevistas, os aspectos éticos recomendados pela Convenção de Helsinque para pesquisa não terapêutica foram respeitados. A natureza, o propósito da pesquisa e os possíveis riscos de participação foram explicados. Os participantes consentiram em contribuir apresentando estados mental, físico e legal que os habilitavam a exercer plenamente seu poder de decisão.

\section{A organização do trabalho offshore na Bacia de Campos (RJ): em meio às adversidades do trabalho real}

A análise dos materiais produzidos nos "encontros sobre o trabalho" nos levou a identificar diversos pontos de confluência entre a visão dos trabalhadores e a literatura acadêmica voltada para o trabalho em turnos em regime offshore. Um elemento central a esse respeito se refere à ideia de que trabalhar nestas condições implica vivenciar simultaneamente fatores diversos que se imbricam em termos dos efeitos ao corpo, ao psiquismo e à vida social. $\mathrm{O}$ relato a seguir nos parece bem ilustrativo ao retratar as diferentes formas de organização da jornada em relação ao intervalo de 0 a 24 horas e suas possíveis repercussões em relação à família e a aspectos variados do dia a dia.

É a questão do turno mesmo que arrasa com você. Arrasa com o organismo. Passei a embarcar e desde essa época eu nunca me adaptei à virada, pra passar a trabalhar à noite. Eu trabalhei um período de meio dia à meia noite, que é o pior turno que tem, porque você fica... quando você está de meio dia à meia noite você tem acesso a tudo, familiares, televisão. Agora quando você está de meia noite ao meio dia, você perde tudo. Porque você entra à meia noite, está todo mundo dormindo, a televisão não tem mais nada pra você ver, você fica, pelo menos até às seis, sete horas da manhã isolado do mundo, porque não tem nada. Você não pode ligar pra uma pessoa pra conversar, a não ser ligar entre uma plataforma e outra. Aí dá 7 horas da manhã, começa aquele alvoroço, todo mundo querendo saber de tudo, o que é que aconteceu, o que é que deixou de fazer, o que é que tem pra fazer. Você larga meio dia acabado, porque a cobrança naquele período de sete ao meio dia, tudo tem que acontecer e tem que resolver. O turno agora que eu estou é de seis e meia à seis e meia. Então, pelo menos, você divide mais. Você larga às seis e meia da tarde, toma um banho, janta, ainda tem com quem você conversar, sua esposa, seus filhos e tal. Mas quando você passa pra trabalhar à noite, você larga seis e meia da manhã, às vezes você quer resolver um problema com banco, você tem que esperar dar dez horas da manhã. Então você tem que ficar acordado ali, esperando, pra você poder ligar, resolver o seu problema e aí... ir dormir, porque você tem que dormir, né? Você sabe que você tem que descansar. Mas eu já procurei até médicos aqui pra saber por que é que eu não consigo. Tem pessoas que largam às seis e meia da manhã, tomam um banho, tomam um café, vai dormir e tem que acordar às 6 e meia da tarde, porque se não o cara continua dormindo, entendeu? No meu caso, não. Eu largo do turno, tomo um banho, tomo um café, vou pra cama, meio dia eu acordo. Onze e meia, meio dia e meia. O pessoal até fala: 'pô, o reloginho seu não erra'. E não tem jeito, eu tenho que acordar pra fazer a refeição. (Petroleiro X)

No que concerne às consequências sociais do trabalho em turnos, Rotenberg (2003) já frisava que o tempo não tem o mesmo valor nas diversas horas do dia ou nos vários dias da semana, pois estudos sobre o valor subjetivo do tempo apontam os horários noturnos como os mais valorizados em relação à vida familiar. Tal afirmativa, que se aplica ao conjunto de trabalhadores em turnos, refere-se à maior ou à menor possibilidade de conciliação entre os horários de trabalho e a convivência com a família. Trata-se, portanto, de um aspecto vivido pelos trabalhadores em turnos em geral, mas que pode se mostrar mais agudo no caso do trabalho em regime de embarque. 
Ressalte-se ainda a noção de que o corpo pode atuar como um relógio "que não erra", o que converge com o principal conceito da cronobiologia, ${ }^{11} \mathrm{o}$ de que os organismos apresentam uma organização temporal. A expressão "você sabe que você tem que descansar" reforça que esta consciência não significa "conseguir descansar" efetivamente, refletindo, neste sentido, uma dificuldade em relação ao sono/descanso não necessariamente partilhada por muitos colegas de trabalho. Assim, de certa maneira, o petroleiro nos remete a diferenças individuais descritas na literatura como subjacentes à tolerância ao trabalho em turnos, muitas das quais envolvendo aspectos do ciclo vigília-sono (MORENO, 2003). Estudos com trabalhadores embarcados revelam diferenças na sincronização dos ritmos (GIBBS et al., 2007), que poderiam explicar formas diferentes de "lidar" com a inversão de horários demandada pela organização do trabalho. Estas diferenças não se restringem unicamente a aspectos da cronobiologia, uma vez que cada trabalhador sofre um conflito particular relativo ao encontro entre suas características individuais e as condições de trabalho (VERDIER; BARTHE; QUÉINNEC, 2003).

Por outro lado, em que pese a contribuição da cronobiologia nas diferenças observadas entre os trabalhadores, deve-se considerar a afirmativa de Monk (2005) em relação à tolerância ao trabalho em turnos, a qual não deve ser vista somente sob o prisma cronobiológico (relacionado aos ritmos circadianos), nem somente relacionada ao sono ou unicamente como uma questão social ou doméstica. Trata-se, segundo o autor, de uma interação complexa desses três fatores, cada qual influenciando os outros dois. A nosso ver, ao mencionar em uma mesma fala as dificuldades relativas à "virada", questões relativas ao contato com a família, assim como diferenças entre os trabalhadores quanto a aspectos do sono, o trabalhador vai ao encontro deste conjunto complexo de fatores vinculados a tais diferenças.

Vale comentar também a diferença de densidade do trabalho dentro de um mesmo turno mencionada no relato, o que nos faz evocar as flutuações presentes na atividade, que se traduzem no compromisso entre as exigências da tarefa e as capacidades funcionais do momento, citadas por Verdier, Barthe e Quéinnec (2003). Nesse sentido, é essencial que os operadores tenham margens de ajuste na execução de seu trabalho, pois os modos operatórios colocados em ação podem diferir de acordo com os horários. Isso nos aponta que os trabalhadores não são passivos diante das dificuldades fisiológicas ou das flutuações de intensidades no trabalho a que são submetidos nos diferentes turnos ou mesmo ao longo de uma jornada. Pelo contrário, devem gerir essas variações por intermédio de um engajamento que se dá por inteiro - corpo biológico, inteligência, afetividade, história de vida e sociabilidade -, tal como assinala Athayde (1999), com base em Montmollin. Ou então, como preferem Schwartz e Durrive (2007), um engajamento do corpo-si. Uma gestão nem sempre simples no contexto do offshore devido à rigidez de procedimentos já mencionada anteriormente.

Considerando o conjunto de problemas aos quais estão expostos os trabalhadores em turnos, a questão da segurança é crítica, mormente quando se considera o quadro de privação do sono, fadiga e necessidade de desempenho de tarefas que demandam atenção e alerta em momentos inadequados do ponto de vista dos ritmos biológicos (FOLKARD; TUCKER, 2003; MONK et al., 1996). Discutindo indicadores de acidentes ao estudar trabalho em turnos noturnos, De Vries-Griever e Meijman (1987, apud ALMEIDA, 2003) encontraram resultados que sugerem que o principal agente de risco seja a presença de trabalhador não adaptado aos turnos. Segundo os autores, esse tipo de trabalhador poderia tornar-se agente de risco para si próprio e para outras pessoas devido às interferências da sonolência tanto na capacidade de detecção de sinais, quanto na de respondê-los adequadamente.

Além disso, parte dos trabalhadores poderia apresentar transtornos de humor, seja de origem biológica (disfunção de ritmos circadianos, perda de sono), seja de origem social. Isso, por sua vez, poderia ser responsável por mudar suas atitudes em relação à operação de máquinas perigosas e ao interesse pela segurança de outras pessoas de tal maneira que, o que poderia ser classificado como irresponsabilidade ou desatenção à segurança, muitas vezes revela-se consequência da exaustão ocasionada pelas condições de trabalho aliadas aos conflitos que se exacerbam em meio à multiplicidade de fatores de risco aí presente. Pode-se pensar então no agravamento desse quadro devido a outros fatores relacionados à gestão do trabalho, tais como os sucessivos embarques sem respeito aos períodos de descanso em terra e o compromisso com os procedimentos de segurança em conflito permanente com as metas de produção. Esta solicitação extrema pelo trabalho pode ter repercussões nefastas para a saúde, impulsionando ao seu limite a capacidade de mobilização do corpo-si. Um movimento inverso àquele de adaptação dos sistemas técnicos ao trabalhador, como já preconizava a Ergonomia da Atividade (WISNER, 1994), e exemplo do grau de tensão que pode se instaurar em função dessa correlação de forças entre o uso de $s i^{12}$ por si e o uso de si pelos outros. O relato abaixo ilustra bem

\footnotetext{
${ }^{11}$ As espécies vivas, nelas incluída a espécie humana, apresentam funções que variam regularmente segundo escalas de magnitude que vão de milisegundos a um ano ou mais (MOSER et al., 2006). Algumas dessas variações tendem a ajustar-se a ciclos ambientais, como o dia-noite e as estações do ano. Essas oscilações, geradas pelo organismo e influenciadas pelo ambiente, são denominadas "ritmos biológicos", entre os quais os mais conhecidos são os ritmos diários ou circadianos. A Cronobiologia, área do conhecimento que se ocupa das características temporais dos organismos, considera a ritmicidade um caráter fundamental da vida, manifestando-se de forma integrada em células, órgãos e sistemas (MENNA-BARRETO, 1999). Os ritmos biológicos compõem o "sistema de temporização", termo utilizado atualmente para fugir da expressão "relógios biológicos", que sugere a ideia de estruturas fisiológicas discretas (MARQUES; MENNA-BARRETO, 1997; MORENO; LOUZADA, 2004; MENNA-BARRETO, 2003).

${ }^{12}$ Todo trabalho, porque é lugar de um problema, convoca um uso de si. Isto quer dizer que não há simples execução, mas uso, convocação de um indivíduo singular com capacidades bem mais amplas que as enumeradas pela tarefa. Trabalhar coloca em tensão o uso de si requerido pelos outros e o uso de si consentido e comprometido por si mesmo (DURRIVE; SCHWARTZ; 2008).
} 
essa situação, cabendo ressaltar a ênfase no reconhecimento das consequências deste tipo de trabalho, como enfatiza o operador:

É o que a gente vê, pelo menos é o que eu vejo lá na unidade em que eu trabalho e em que eu trabalhava. Pessoas com surtos de irritação e com atitudes de deixar a segurança pra lá, que é absurdo o cara está naquela situação e com o conhecimento que ele tem, tomar uma determinada atitude. E ai está tomando aquela atitude por quê? Por que ele é assim? Porque vai ter muita gente que vai dizer: 'Ah... é porque ele é assim’. Não é. Porque a condição de trabalho dele deixou ele assim. E é incrível como a maioria das pessoas, elas subestimam o que o nosso tipo de trabalho é capaz de fazer com a gente. Eu hoje estou... já tenho a clareza de que eu não consigo ficar muito mais tempo embarcado. $\mathrm{Eu}$ estou chegando mesmo ao meu limiar de condição de trabalho embarcado [...] (Petroleiro Y)

A situação é mais grave quando se considera que o regime de embarque é diferenciado: 14/21 para funcionários efetivos e 14/14 para os de empresas terceirizadas. Em meados dos anos 1990, Pessanha (1994) já indicava a insatisfação dos trabalhadores efetivos com o regime em vigor (14/21), predominando amplamente a defesa pelo regime de 10/20 dias, o que também foi confirmado, posteriormente, por Rodrigues (2001) e, mais recentemente, por nós (FIGUEIREDO; ALVAREZ, 2007). E o que dizer, então, do esquema que rege o embarque dos terceirizados, que têm uma semana a menos de descanso, conforme indicado acima? É certo que estão submetidos a um desgaste maior e, como agravante, há circunstâncias em que estes intervalos não são respeitados, lançando-se mão de uma espécie de "banco de horas" que funciona como instrumento de pressão de algumas chefias para que, mesmo alguns trabalhadores efetivos, embarquem antes do término do seu período de descanso.

[...] Eu estou numa escala meio maluca, porque a minha área, é como eu falei pra vocês, eu trabalho sozinho no turno, com o supervisor e nós estamos entrando nessa fase aí de férias, né? Porque a maioria gosta de tirar férias nesse período de dezembro a março, e aí com... cai naquela coisa do "quando eu preciso de ti, eu te convoco'. Então a gente vai ficar fazendo praticamente quatorze por quatorze [o funcionário é efetivo e não terceirizado]. Pelo menos estão respeitando os quatorze dias de folga mínimos. (Petroleiro Y)

Esta fala do operador remete a achados anteriores, segundo os quais, por diversas vezes, tanto as normas dos tempos de embarque, como as de folga não são respeitadas. Constatam-se ampliação do período de embarque, redução do período de folga durante o desembarque (seja para a realização de cursos e treinamentos, seja em função da convocação para outro embarque) ou, ainda, acréscimo de horas trabalhadas ao longo da jornada diária. As razões que estariam na gênese deste processo são variadas e algumas delas já foram apontadas por nós em publicações anteriores (FIGUEIREDO; ATHAYDE, 2004, FIGUEIREDO; ALVAREZ, 2007; MARTINS, 2005; PEREIRA, 2007;
SUAREZ, 2008). A nosso ver, esses aspectos organizacionais são extremamente relevantes para a discussão sobre confiabilidade em sistemas sociotécnicos complexos. Há, inclusive, casos que beiram o aviltamento, extrapolando a definição de horários "formais e informais" (VERDIER; BARTHE; QUÉINNEC, 2003), quando empresas convocam trabalhadores para embarcar poucos dias depois de chegarem em terra - ou até mesmo no dia seguinte àquele do desembarque - contribuindo para agravar o risco potencial de acidentes ou de consequências nefastas à saúde mental:

[...] Já me chamaram pra embarcar na época em que tinha uma quebra de recorde desses. E como eles não queriam arriscar uma parada de produção por falta de operador, me convocaram. Eu estava de folga e me convocaram dessa forma. Porque eu estava com um saldo lá, negativo, e que eu estava sendo convocado, que aquilo era uma convocação pra embarcar. E aí eu disse: 'Olha, eu não estou em condições de embarcar. Eu não estou em condições psicológicas pra embarcar’. E não estava mesmo. Eu estava cansado, com problemas, minha mãe doente e... enfim... não estava com cabeça pra embarcar mesmo. E aí fiquei mais irritado ainda por ele ter falado sobre a questão da convocação, dele usar esse termo de convocação. E aí eu falei: 'Olha, eu não tenho condições psicológicas pra embarcar'. (Petroleiro Y)

Também há casos de profissionais que, por vezes, passam mais de 30 dias embarcados, mesmo não fazendo parte da "legião de estrangeiros", que, usualmente, por residirem em outros países, submetem-se a regimes especiais de embarque (mais longos).

Tem cara que eu conheço... Aí vem, aí envolve problemas de segurança também, eles não têm controle sobre isso. Você tem que ser 14 por 14, é lei. Mas o cara embarca numa plataforma aqui e fica 14 dias. Desembarca e embarca noutra e fica... Fica lá 12 dias e aí desembarca. E aí, eu conheço uns caras que eles... Eu não sei o que é que pensam da vida, e compra outra casa e vai e vai e acaba acontecendo um acidente, porque ele está de cabeça cheia [...] (Petroleiro Z)

Estes arranjos não são raros e há aqueles que são completamente insólitos. É o caso de trabalhadores que podem se ver na condição de terem que se manter em estado de vigília por períodos bem longos, por 24 horas, 48 horas e até mesmo 72 horas ou mais! Esse é especialmente o caso da empresa Schlumberger, segundo alguns de seus ex-trabalhadores, que, embora subcontratada da Petrobras na região, ocupa a condição de grande corporação multinacional, líder mundial no ramo em que atua.

Causou-nos perplexidade quando tomamos conhecimento, por intermédio dos mesmos ex-trabalhadores, que esta empresa ministra cursos em que são ensinadas "técnicas de administração do sono", visando municiar seus funcionários da forma que julga mais apropriada para o enfrentamento de tais condições de trabalho. Em outras palavras, trata-se de como fazer para romper com os limites que a necessidade de sono nos impõe, 
extrapolando as referências concernentes à ampliação da jornada de trabalho e à reprodução da força de trabalho. Provavelmente, ancorados nos estudos das fases do sono e visando reduzir os acidentes de trajeto, que, possivelmente em função dessas extrapolações dos tempos de jornada, alcançaram níveis altíssimos, a empresa, desde 1991, realiza estudos e implanta programas que relacionam performance à fadiga tentando combater a "síndrome do comportamento automático". Assim, no curso acima citado, há indicações de melhores tempos de duração de cochilos e a apresentação de gráficos, como o exposto a seguir, com demonstrativos da baixa de vigília correlacionando-os com os dias sem dormir (Gráfico 2). Na empresa citada, um de nossos interlocutores chegou a permanecer até 4 noites sem retornar à base, portanto, ao longo de 5 dias, seu sono se resumiu à realização de cochilos de duração variada e em horários irregulares, ditados pela intensidade da demanda do processo de trabalho.

Em tal contexto, as atividades desenvolvidas nas situações reais de trabalho exigem que se acionem estratégias, que se "reinvente" o metabolismo, renormatizando as capacidades energéticas para poder fazer frente a uma jornada praticamente ininterrupta, com os profissionais lidando com equipamentos sofisticados e de altíssimo custo:

[...] O que eu lembro que a gente tinha do trabalho, quer dizer, pra manter a gente acordado, é que, por exemplo, preparar todo esse trabalho, normalmente, demorava uma hora. Mas era uma hora de você terminar completamente suado e tenso, exercício físico. Então você descia a ferramenta pra umas 5 horas de trabalho, 5, 6 horas, tá? Na primeira hora, você ainda está suado, está preparando a ferramenta e tudo. Depois vêm duas horas pesadas, e depois você já está tirando a ferramenta, já está finalizando os relatórios, finalizando tudo. E ai você volta pra fora, pra trabalhar... Então são períodos de 6 a 8 horas, que a cada 6 ou 8 horas, você tem um trabalho bem pesado. Então esses te acordam bastante. Se você pega, justo... 3 horas da manhã e começa a fazer um trabalho pesado desses, já de 3 às 5 , você vira a noite sem nem perceber. Depois de um tempo, daí você sente, começa a perder a fome, a gente sentia que depois do segundo dia, terceiro dia, a gente começava a comer menos, porque você já não [...] começa a se sentir pior, sei lá, estranho [...] (Petroleiro K)

Pelo que constatamos em relação a esta grande corporação, este tipo de trabalhador não é formado apenas para atuar no offshore, pois ele também atua em terra (onshore). Tal como os "trecheiros" da construção civil (que vivem no "trecho", de um canto a outro), eles devem estar preparados para intervir nos mais variados locais, em condições extremas. São os "trecheiros do ouro negro" como se percebe na continuação do relato anterior:

Petroleiro K: Vamos supor, dessa vez que eu fiquei 5 dias, depois do terceiro, quarto dia, eu já não sentia sono. Não sei, estava estranho. O corpo já não sentia sono, você já não estava mais sentindo as coisas.

Pesquisador B: Mas você não sentia tipo um anestesiamento, alguma coisa assim no corpo?

Petroleiro K: A coisa é que esse trabalho, essa vez que eu fiquei 5 dias não foi 1 trabalho foram 7 trabalhos. Era de um lugar para o outro: fazia, desmontava, preparava tudo, ia pra o outro lugar, fazia, desmontava [...] Então, uma hora os caras falaram: 'Não, tá bom, termina e volta pra casa'. E aí a gente estava longe, tinha terminado de noite, e a gente falou: 'Vamos ficar num hotel por aqui, amanhã a gente volta'. Aí nisso a gente foi comer, tinha ficado os últimos dois dias, praticamente, sem comer, fomos comer num lugar bom, mas comemos muito. E eu passei a noite toda vomitando, no outro dia fiquei com febre, quer dizer, todas as defesas tinham ido lá em baixo, mas acho que provavelmente a pressão e a tensão eram tantas que ainda me mantinham em pé. Quando relaxou, aí eu fiquei doente... No dia seguinte inteiro eu fiquei em casa com febre, no outro dia já fui trabalhar de novo. Mas muitas vezes você ia pra casa e dormia umas 12 horas, mas eu nunca fui de dormir mais de 8 horas. Lá, era comum eu dormir 12 horas, 13 horas... Comum, depois de você ficar mais de dois dias sem dormir, você vai pra casa $[\ldots]$

A situação é descrita pelo petroleiro como "estranha”, pois passava a perder a fome e o sono e "já não estava sentindo as coisas”. Esta situação inteiramente

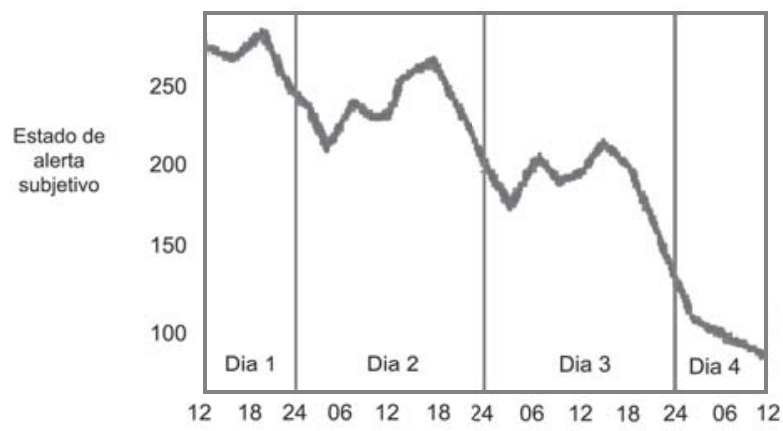

Gráfico 2 Variação dos ciclos de estado de alerta durante privação do sono ao longo de 4 dias

Fonte: <http://www.ptac.org/has/dl/hasw0104.pdf> 
atípica ocorre porque esta empresa costuma não adotar o esquema clássico de revezamento em indústrias de processo contínuo com duas equipes que se alternam ao longo das $24 \mathrm{~h}$, cada uma cumprindo metade desta jornada (12h). Trabalha-se, literalmente, 24 horas por dia, a qualquer hora, 7 dias por semana, sob um regime mensal que prevê 4 dias de férias e mais 4 de descanso. ${ }^{13}$ É comum acumular-se alguns poucos ou vários dias de férias e de descanso, assim os vender, dependendo da chefia local, das regras predominantes no país. Como o engenheiro em questão atuava no exterior, para garantir suas vindas ao Brasil de tempos em tempos, negociou um regime que era de dois meses e meio de trabalho e 3 semanas de descanso. ${ }^{14}$ Contudo, em contextos de grande demanda de serviços, pode-se ficar até 3 ou 4 meses trabalhando direto, sem descansar nenhum dia, como chegou a ocorrer com a técnica e com o engenheiro escutados. ${ }^{15}$

Portanto, cabe enfatizar que o contexto delineado até aqui, na exploração e na produção offshore, torna-se ainda mais crítico quando adicionamos aos fatores de risco mais nítidos tais fatores de cunho organizacional - que influenciam decisões e ações em casos específicos, tal como assinalado por Paté-Cornell (1993) - ou mesmo de cunho antropotecnológico, como nos aponta Wisner (1997).

Frente a esse quadro, que, em certos momentos, traz à memória a possibilidade de ocorrência de um incidente ou acidente, por vezes de uma catástrofe, como a de Piper Alpha (PATÉ-CORNELL, 1993; WOOLFSON, 1996), na qual vieram a falecer 167 dos 223 tripulantes, entende-se a presença constante de certa dose de "tensão nervosa”, tal como observa Dejours (1993) ao fazer menção ao discurso dos trabalhadores da indústria petroquímica francesa. Compreende-se também o papel crucial que têm os sistemas defensivos aí engendrados, sem os quais seria insuportável a permanência em tais ambientes, pois estes permitem aos trabalhadores mitigar a representação que possuem dos riscos e elaborar informalmente regras que ajudarão a amalgamar sua coesão enquanto coletivo de trabalho.

Nesta direção, deve-se assumir, tal como já sublinhamos anteriormente (FIGUEIREDO; ATHAYDE, 2004), que tais situações requerem uma profunda mobilização não apenas cognitiva, mas também psicoafetiva para lidar a contento com as adversidades que o trabalho offshore evoca. E, diante da indispensável intervenção dos trabalhadores visando a contornar as insuficiências da orga- nização prescrita, rearranjando-as no curso do trabalho efetivamente realizado, deparamo-nos com a mobilização da iniciativa, da inventividade e da cooperação dos trabalhadores (DEJOURS, 1992) e com aquilo que de positivo tal mobilização aporta para a confiabilidade dos sistemas complexos. Convocam-se à cena do trabalho a "inteligência astuciosa” (ou do corpo, da prática), bem como aptidões da ordem da mètis (DETIENNE; VERNANT, 2008). Em boa medida, é em razão desta mobilização que inúmeras falhas latentes não se tornam acidentes ativos.

\section{Considerações finais: síntese para conti- nuação do debate}

Os múltiplos aspectos citados nos relatos anteriores abrem um questionamento sobre os usos de si desses petroleiros e a consequente convocação do corpo-si de maneiras diferenciadas. Com efeito, a natureza do trabalho embarcado aciona permanentemente estratégias para lidar com inúmeras adversidades, tais como: a ausência de convívio social e familiar durante os embarques; os repousos insuficientes; a demanda cognitiva elevada, em especial das tarefas complexas; a dessincronia dos sistemas de temporização e as repercussões cronobiológicas; as relações conflituosas com os superiores etc. Para nós, está claro que cada petroleiro poderá criar possibilidades singulares de convívio com as vicissitudes que caracterizam o trabalho offshore e que esse conjunto de fatores não resultará, inexoravelmente, em acidente, doença ou sofrimento patogênico. Entretanto, alguns dos fatores aqui implicados, além de outros aspectos apontados anteriormente, relacionados à organização do trabalho, abrem flanco, a nosso ver, para a potencialização do risco em um ambiente já bastante perigoso.

Um dado a corroborar nossa análise diz respeito à importância que vem sendo dada por alguns especialistas (PATÉ-CORNELL, 1993; WISNER, 1994; PERROW, 1999; LLORY, 1999) aos chamados "fatores organizacionais” na análise de acidentes ampliados com repercussão internacional, ocorridos nas últimas décadas, envolvendo os chamados sistemas sociotécnicos complexos. Constata-se ainda que, na ocorrência de alguns destes desastres, fatores ligados ao trabalho em turnos e noturno e à operação contínua mostraram-se intervenientes em alguma medida. Vale mencionar os acidentes nucleares de Three Mile Island (1979) e Chernobyl

\footnotetext{
${ }^{13}$ Apenas para se ter uma rápida base de comparação, em um esquema tradicional de trabalho, estes 8 dias corresponderiam aos 4 finais de semana do mês. Só que no regime tradicional, em nosso país, por exemplo, além dos finais de semana, não são computados como dias de trabaIho, os feriados e os 30 dias de férias.

${ }^{14}$ Se a cada mês eles têm direito a 4 dias de férias e a 4 de descanso, em dois meses e meio tem-se direito de usufruir 10 dias de férias e 10 de descanso (20 dias), ou seja, em torno de 3 semanas de folga.

${ }^{15}$ Note-se que, apesar das flagrantes burlas à legislação trabalhista, de acordo com alguns trabalhadores, diversos funcionários optam por não acionar a empresa para não ficarem “queimados no meio", visto haver inúmeros casos de terceirizados que circulam pelas empresas de seu respectivo ramo de atuação no setor petrolífero. Cabe observar ainda que tais esquemas são adotados com maior intensidade em países em que a legislação/fiscalização vigente não coíbe ou mostra-se ineficaz para coibir a contento tais situações.
} 
(1986), o desastre de Bhopal (1984), a explosão da plataforma Piper Alpha (1988) e o derramamento de óleo do petroleiro Exxon Valdez (1989).

Um dado pontual, mas que nos ajuda a vislumbrar a premência de se agir sobre as questões vinculadas à organização do trabalho e suas implicações para a saúde e segurança, diz respeito à empresa (Schlumberger) que se vale das já citadas "técnicas de administração do sono”. Constatamos que tal expediente não a impediu de ser agraciada com certificações do tipo OHSAS 18001 (Sistema de Gestão - assim como a ISO 9000 e a ISO 14000 - porém com o foco voltado para a saúde e segurança no trabalho) e de receber prêmios ligados à sua atuação na área de responsabilidade social (ANUÁRIO BRASILEIRO DE PROTEÇÃO, 2006; SCHULUMBERGER:..., 2004). Este dado nos parece assaz interessante, pois nos permite constatar como também, no caso da indústria do petróleo, os sistemas de certificação em gestão do trabalho e em saúde e segurança estão defasados daquilo que efetivamente se verifica no curso da atividade e no âmbito das condições concretas de segurança e saúde do trabalhador. O paradoxo não deve ser visto com surpresa quando se enfocam os mundos do trabalho globalizado e, mais particularmente, o setor petrolífero, pois mesmo no contexto desta indústria no Mar do Norte, que verificou avanços na esfera da saúde e segurança após a catástrofe de Piper Alpha, os desafios não são de pequeno alcance, como atestam Woolfson e Beck (2000).

Da mesma forma, apesar de a Petrobras informar que seu programa de SMS (Segurança, Meio Ambiente e Saúde) é o mais caro do mundo, tendo consumido R\$ 10 bilhões (MIGUEZ, 2010) de 2000 para cá, os indicadores de acidentes graves e fatais ainda se mostram preocupantes, sobretudo em se tratando dos trabalhadores terceirizados. Se olharmos à lupa todo o Sistema Petrobras, o saldo não é nada abonador: 282 mortes de 1995 a 2009, sendo 227 de trabalhadores terceirizados, conforme o último levantamento divulgado pela FUP (FEDERAÇÃO ÚNICA DOS PETROLEIROS, 2010). O caso recente envolvendo petroleiros da empresa Brasdril, ou a serviço desta, é emblemático. Em outubro de 2009, na plataforma SS-55, um deles (funcionário da Baker Hughes que prestava serviço para a Brasdril) sofreu amputação do braço após se acidentar na operação de um dispositivo denominado "secador de cascalho" (SINDICATO DOS PETROLEIROS DO NORTE FLUMINENSE, 2009). Cerca de seis meses depois, em abril de 2010, a operação do mesmo tipo de dispositivo na plataforma SS-52 também resultou em acidente grave, só que, desta feita, o petroleiro sofreu amputação da perna (SINDICATO DOS PETROLEIROS DO NORTE FLUMINENSE, 2010a). Em seguida, no mês de maio de 2010, apesar de se tratar de treinamento, em uma manobra de abandono da sonda de perfuração Ocean Ambassador, que terminou em queda da baleeira no mar, dois trabalhadores perderam a vida e outros dois se feriram e foram hospitalizados. No caso deste último evento, a Brasdril operava o navio sonda a serviço da empresa OGX (SINDICATO DOS PETROLEIROS DO NORTE FLUMINENSE, 2010b).

Acerca das possibilidades de intervenção no regime de turnos, vale citar o caso de uma das plataformas estudadas por Rodrigues (2001). Nele, as equipes da ponte de comando e da operação de DP (posicionamento dinâmico) trabalhavam em turnos fixos de 12 horas, com dois operadores por turno, assumindo sempre um deles com previsão de descanso a cada 6 horas devido às elevadas solicitações cognitivas das tarefas associadas aos níveis de alerta exigidos nesta atividade, ao que acrescentamos as solicitações de ordem psíquica. Eram 8 estrangeiros os técnicos de DP, 4 a bordo e 4 de folga, em regime de 28 dias de trabalho e 28 dias de folga. Como os turnos são defasados de 6 horas, a cada intervalo de 6 horas entra em serviço alguém descansado e que passa a fazer dupla com um companheiro que está de serviço há 6 horas. Os turnos são de $0 \mathrm{~h}$ às $12 \mathrm{~h}$, de $6 \mathrm{~h}$ às $18 \mathrm{~h}$, de $12 \mathrm{~h}$ às $24 \mathrm{~h}$ e de $18 \mathrm{~h}$ às $6 \mathrm{~h}$.

Esse nos parece um bom exemplo de uma mudança na organização do trabalho que busca mitigar os "contraintes" da elevada carga de trabalho presente em tais situações e que aponta para a necessidade de uma maior participação dos trabalhadores neste tipo de decisão. Devemos relembrar também que o regime preferido pelos petroleiros apontava para limitar-se o período de embarque a 10 dias, visto que predominava a avaliação de que, após o $10^{\mathrm{O}}$ dia de embarque, com o desgaste, a tendência era de que se deteriorassem as relações interpessoais a bordo (PESSANHA, 1994; RODRIGUES, 2001). Resta saber até que ponto houve algum avanço em relação a temáticas desta natureza na Bacia de Campos - como o trabalho em turnos e o confinamento -, visto que, em sua pesquisa, Rodrigues (2001, p. 138) chamava a atenção, com o conhecimento de quem atuava no interior da organização e cujo estudo tinha ênfase no trabalho em turnos, para o fato de que ambas eram questões "tratadas empiricamente, como se fazia nos primórdios da atividade offshore, sem nenhum uso de subsídios científicos".

Por fim, é oportuno salientar, por um lado, que a aprovação do Anexo II (Plataformas e Instalações de Apoio) da Norma Regulamentadora $n^{\circ} 30$, em maio de 2010, se apresenta como um instrumento importante na luta dos petroleiros pela melhoria das condições de trabalho no offshore brasileiro. E, de outro lado, que o acidente ocorrido cerca de um mês antes com a plataforma Deepwater Horizon, no Golfo do México, em águas ultraprofundas - no qual onze trabalhadores perderam a vida, a unidade naufragou em chamas e os danos ambientais só são comparáveis às piores catástrofes do setor -, dá fortes indícios de que essa luta ainda está longe de acabar, considerando o horizonte que se descortina em nosso país com a exploração do petróleo da camada pré-sal. 


\section{Agradecimentos}

Agradecemos especialmente ao bolsista de iniciação científica Rafael de Azevedo Branco por suas contribuições para a finalização deste artigo.

\section{Contribuições de autoria}

Os dois primeiros autores construíram o projeto de pesquisa, coletaram e analisaram os dados e contribuíram para a redação do artigo. A terceira autora analisou os dados e contribuiu para a redação do artigo.

\section{Referências}

ÂKERSTEDT, T. Wide awake at odd hours - Shift work, time zones and burning the midnight oil. Stockholm: Swedish Council for Work Life Research, 1996.

ALALUF, M. Le travail du temps. In: TERSSAC, G; TRENBLAY, D. G. (Dirs.). Où va les temps du travail?. Toulousse: Octares, 2000. p. 204-216.

ALMEIDA, I. M. Desempenho e segurança no trabalho em turnos e noturno. In: FISCHER, F.; MORENO, C. R.; ROTENBERG, L. (Org.). Trabalho em turnos e noturno na sociedade 24 horas. São Paulo: Atheneu, 2003. p. 159-186.

ANUÁRIO BRASILEIRO DE PROTEÇÃO. Revista Proteção. Novo Hamburgo, 2006. Edição especial.

ATHAYDE, M. Psicologia e trabalho: que relações? In: JACÓ-VILELA, A; MANCEBO, D. (Org.). Psicologia social: abordagens sócio-históricas e desafios contemporâneos. Rio de Janeiro: EdUERJ, 1999.

ATHAYDE, M.; BRITO, J.; NEVES, M. (Org.). Caderno de textos: programa de formação em saúde, gênero e trabalho nas escolas. João Pessoa: Editora Universitária/ UFPB, 2003.

BJORVATN, B. et al. Subjective and objective measures of adaptation and readaptation to night work on an oil rig in the North Sea. Sleep, v. 29, n. 6, p. 821-829, 2006.

BOIVIN, D. B.; TREMBLAY, G. M.; JAMES, F. O. Working on atypical schedules. Sleep Medicine, v. 8, n. 6, p. 578589, 2007.

CHEN, W. Q.; WONG, T. W.; YU, T. K. Influence of occupational stress on mental health among Chinese off-shore oil workers. Scandinavian Journal of Public Health, v. 37, n. 7, p. 766-773, 2009.

CLOT, Y. A função psicológica do trabalho. Petrópolis: Vozes, 2006.

COREN, S. Sleep thieves: an eye-opening exploration into the science and mysteries of sleep. New York: The Free Press, 1996.

DANIELLOU, F. Introdução: Questões epistemológicas acerca da ergonomia. In: DANIELLOU, F. (Org.). $A$ ergonomia em busca de seus princípios. São Paulo: Edgard Blücher, 2004. p. 1-13.
DE VRIES-GRIEVER, A. H. G.; MEIJMAN, T. F. The impact of abnormal hours of work on various models on human costs of performance. Ergonomics, v. 30, n. 9 p. 1287-1299, 1987.

DEJOURS, C. Pathologie de la communication, situation de travail et espace public: le cas du nucléaire. In: Raison pratiques. 3. ed. Paris: Ècole des Hautes Études en Sciences Sociales, 1992. p. 178-201.

Travail: usure mentale, de la psychopathologie à la psychodynamique du travail. 9. ed. augm. Paris: Bayard, 1993.

. Le facteur humain. Paris: Presses Universitaires de France, 1995.

. Addendum: da psicopatologia à psicodinâmica do trabalho. In: LANCMAN, S.; SZNELWAR, L. (Org.). Christophe Dejours: da psicopatologia à psicodinâmica do trabalho. 2. ed. Rio de Janeiro: Fiocruz; Brasília: Paralelo 15, 2008. p. 49-106.

DÉTIENNE, M.; VERNANT, J. Métis: as astúcias da inteligência. São Paulo: Odysseus, 2008.

DROGARIS, G. Major accident reporting systems: lessons learned from accidents notified. Londres: Elsevier, 1993.

DURRIVE, L.; SCHWARTZ, Y. Glossário da ergologia. Laboreal, v. 4, n. 1, p. 23-28, 2008. Disponível em: $<$ http://laboreal.up.pt/revista/artigo.php > . Acesso em: FEDERAÇÃO ÚNICA DOS PETROLEIROS. Petroleiros na luta por segurança. Primeira mão, Rio de Janeiro, n. 940, p. 1, 21-28 maio 2010.

FIGUEIREDO, M. O trabalho de mergulho profundo em instalações petrolíferas offshore na Bacia de Campos: a guerra de 'highlander' contra Leviatã. 2001. 288 f. Tese (Doutorado em Engenharia de Produção)-COPPE; Universidade Federal do Rio de Janeiro, Rio de Janeiro, 2001.

FIGUEIREDO, M.; ALVAREZ, D. Reestruturação produtiva, terceirização e relações de trabalho na indústria petrolífera offshore da Bacia de Campos (RJ). Gestão \& Produção, São Paulo, v. 14, n. 1, p. 55-68, jan./abr., 2007. 
FIGUEIREDO, M.; ATHAYDE, M. Coletivos de trabalho e componentes subjetivos da confiabilidade em sistemas sociotécnicos complexos: considerações a partir da situação de trabalho em mergulho profundo na Bacia de Campos/RJ. In: FIGUEIREDO, M.; ATHAYDE, M.; BRITO, J. (Org.). Labirintos do trabalho: interrogações e olhares sobre o trabalho vivo. Rio de Janeiro: DP\&A, 2004.

. Organização do trabalho, subjetividade e confiabilidade na atividade de mergulho profundo. Produção, São Paulo, v. 15, n. 2, p. 172-186, 2005.

FIGUEIREDO, M. et al. Productive reorganization, outsourcing, and work relations in the offshore oil industry in the Campos Basin, Rio de Janeiro. New Solutions, v. 18, n. 4, p. 459-480, 2008.

FISCHER, F. M.; MORENO, C. R. C.; ROTENBERG, L. Trabalho em turnos e noturno na sociedade 24 horas. São Paulo: Atheneu, 2003.

FISCHER, F.; PARAGUAY, A.; BRUNI, A. Working conditions, work organization and consequences for health of Brazilian petrochemical workers. International Journal of Industrial Ergonomics, v. 21, n. 3-4, p. 209219, 1998.

FISCHER, F. et al. Implementation of 12-hour shifts in a Brazilian petrochemical plant: impact on sleep and alertness. Chronobiology International, New York, v. 17, n. 4, p. 521-537, 2000.

FOLKARD, S.; TUCKER, P. Shift work, safety and productivity. Occupational Medicine, London, v. 53, n. 2, p. 95-101, 2003.

FREITAS, C. M.; SOUZA, M. F.; MACHADO, J. M. H. (Org.) Acidentes industriais ampliados: desafios e perspectivas para o controle e a prevenção. Rio de Janeiro: Fiocruz, 2000.

FREITAS, C. et al. Acidentes de trabalho em plataformas de petróleo da Bacia de Campos, Rio de Janeiro, Brasil. Cadernos de Saúde Pública, Rio de Janeiro, v. 17, n. 1, p. 117-130, 2001.

GARDNER, R. Overview and characteristics of some occupational exposures and health risks on offshore oil and gas installations. Annals of Occupational Hygiene, New York, v. 47, n. 3, p. 201-210, 2003.

GIBBS, M. et al. Predicting circadian response to abrupt phase shift: 6-sulphatoxymelatonin rhythms in rotating shift workers offshore. Journal of Biological Rhythms, v. 22, n. 4, p. 368-370, 2007.

HANECKE, K. et al. Accident risk as a function of hour at work and time of day as determined from accident data and exposure models of German working population. Scandinavian Journal of Work, Environment and Health, v. 24, suppl. 3, p. 43-48, 1998.

HARRINGTON, J. M. Health effect of shift work and extended hours of work. Occupational and Environmental Medicine, London, v. 58, p. 68-72, 2001.
HONRADO, G. I.; MROZOVSKY, N. Interaction between periodic sociosexual crues and light-dark cycles in controlling the phasing and activity rhythms in goldenhamsters. Ethology, Ecology and Evolution, v. 3, n. 3, p. 221-231, 1991.

KNUTSSON, A. Health disorders of shift workers. Occupational Medicine, London, v. 53, n. 2, p. 103-108, 2003.

KOGI, K. Linking better shiftwork arrangements with safety and health management systems. Revista de Saúde Pública, São Paulo, v. 38, p. 72-79, 2004. Suplemento.

LEITE, R. M. S. C. O trabalho nas plataformas marítimas de petróleo na Bacia de Campos: a identidade do trabalhador offshore. 2006. 232 f. Dissertação (Mestrado em Serviço Social)-Universidade Federal Rio de Janeiro, Rio de Janeiro, 2006.

LEPLAT, J.; TERSSAC, G. Les facteurs humains de la fiabilité dans le systemes complexes. Tolouse: Octarès Éditions, 1990.

LEWY, H.; NAOR, Z.; ASHKENAZI, I. E. From ultradian to infradian rhythms: LH release patterns in vitro. Chronobiology International, v. 16, n. 4, p. 441-450, 1999.

LLORY, M. Acidentes industriais: o custo do silêncio. Rio de Janeiro: Multimais, 1999.

LUCENA, C. Tempos de destruição: educação, trabalho e indústria do petróleo no Brasil. Campinas: Autores Associados; Uberlândia: EdUFU, 2004.

MARQUES, N.; MENNA-BARRETO, L. (Ed.)

Cronobiologia: princípios e aplicações. São Paulo: Edusp; Rio de Janeiro: Fiocruz, 1997.

MARTINS, L. Diagnóstico da terceirização e sua relação com as áreas de saúde, meio ambiente e segurança na indústria petrolífera offshore na Bacia de Campos. 2005. 132 f. Dissertação (Mestrado em Engenharia de Produção)-Escola de Engenharia, Universidade Federal Fluminense, Niterói, 2005.

MAUTHNER, N. S.; MACLEAN, C.; MCKEE, L. 'My dad hangs out of helicopter doors and takes pictures of oil platforms': children's accounts of parental work in the oil and gas industry. Community, Work \& Family, v. 3, n. 2, p. 133-162, 2000.

MENNA-BARRETO, L. Human Chronobiology. Annual Review of Biomedical Sciences, Botucatu, v. 1, p. 103132, 1999.

. Cronobiologia humana. In: FISCHER, F. M.; MORENO, C. R.; ROTENBERG, L. (Org). Trabalho em turnos e noturno na sociedade 24 horas. São Paulo: Atheneu, 2003.

MIGUEZ, R. SMS: a indústria já entende essa mensagem. TN Petróleo - Revista Brasileira de Tecnologia e Negócios do Petróleo, Gás, Petroquímica, Química, Química Fina e Biocombustível, v. 12 n. 70, p. 46-51, jan./fev. 2010. 
MONK, T. H. Shift work: basic principles. In: KRYGER, M. H.; ROTH, T.; DEMENT, W. C. (Ed.). Principles and practice of sleep medicine, 4 . ed. Philadelphia: WB Sauders Company, 2005. p. 673-679.

MONK, T. H. et al. Circadian determinantes of the postlunch dip in performance. Chronobiology International, v. 13, n. 2, p. 123-133, 1996.

MORENO, C. R. C. O sono e estratégias relativas ao sono para lidar com os horários de trabalho. In: FISCHER, F; MORENO, C. R.; ROTENBERG, L. (Org.). Trabalho em turnos e noturnos na sociedade 24 horas. São Paulo: Atheneu, 2003.

MORENO, C. R. C.; LOUZADA, F. M. What happens to the body when one works at night?. Cadernos de Saúde Pública, Rio de Janeiro, v. 20, n. 6, p. 1739-1745, 2004.

MORRICE, J. K. et al. Oil wives and intermittent husbands. British Journal of Psychiatry, v. 147, n. 5 p. 479-483, 1985.

MOSER, M. et al. Why life oscillates - Biological rhythms and health. In. INTERNATIONAL CONFERENCE OF IEEE ENGINEERING IN MEDICINE AND BIOLOGY SOCIETY, 28., 2006, New York. Proceedings... New York, NY: IEEE, 2006. p. 424-428.

NAVILLE, P. Temps et technique: les structures de la vie de travail. Genève, Paris: Librairie Droz, 1972.

NOËL, S. Morbidity of irregular work schedules. Revue Médicale de Bruxelles, v. 30, n. 4, p. 309-317, 2009.

ODDONE, I. La communauté scientifique élargie. Revue Société Française, n. 10, p. 28-33, jan./fév./mars 1984.

PARKES, K. R. Working hours in the offshore petroleum industry - current knowledge and research needs regarding extended work periods and shift work offshore. In: CONFERENCE ON WORK TIME ARRANGEMENTS IN THE PETROLEUM INDUSTRY, 2007. Noruega: Petroleum Safety Autority, 2007.

PARKES K. R.; CARNELL, S. C.; FARMER, E. L. 'Living two lives': perceptions, attitudes and experiences of spouses of UK offshore workers. Community, Work and Family, v. 8, n. 4, p. 413-437, 2005.

PATÉ-CORNELL, M. Learning from the piper alpha accident: a postmortem analysis of technical and organizational factors. Risk Analysis, v. 13, n. 2, p. 215232, 1993.

PEREIRA, R. Contribuições da lógica de serviço e do modelo da competência para o programa de segurança, meio ambiente e saúde (SMS) na indústria petrolífera offshore na Bacia de Campos. 2007. 113 f. Dissertação (Mestrado em Engenharia de Produção)-Escola de Engenharia, Universidade Federal Fluminense, Niterói, RJ, 2007.

PERROW, C. Normal Accidents: living with high-risks technologies. Princeton: Princeton University Press, 1999.

PESSANHA, R.M. O trabalho "offshore”: inovação tecnológica, organização do trabalho e qualificação do operador de produção na Bacia de Campos. 1994. 199 f. Dissertação (Mestrado)-COPPE, Universidade Federal do Rio de Janeiro, Rio de Janeiro, 1994.

QUÉINNEC, Y. Horário. Laboreal, v. 3, n. 2, p. 90-91, 2007. Disponível em: <http://laboreal.up.pt/revista/ artigo.php?id=48u560TV6582234234335473732 > . Acesso em: 11 dez. 2009.

REASON, J. L'erreur humaine. Paris: PUF, 1993.

RODRIGUES, V. F. Relações de trabalho em unidades de perfuração marítima; estudo de caso com ênfase no trabalho em turnos. 2001. 168 f. Dissertação (Mestrado em Engenharia de Produção)-Universidade Federal de Alfenas, Alfenas, 2001.

RODRIGUES, V.; FISCHER, F. M.; BRITO, M. J. Shift work at a modern offshore drilling rig. Journal of Human Ergology, Tokyo, v. 30, n. 1-2, p. 167-172, 2001.

ROSS, J. K. Offshore industry shift work - health and social considerations. Occupational Medicine, Londres, v. 59, n. 5, p. 310-315, 2009.

ROTENBERG, L. Aspectos sociais da tolerância ao trabalho em turnos e noturno, com ênfase nas questões relacionadas ao gênero. In: FISCHER, F; MORENO, C. R.; ROTENBERG, L. (Org.). Trabalho em turnos e noturno na sociedade 24 horas. São Paulo: Atheneu, 2003. p. 53-63.

RUNDMO, T. Associations between risk perception and safety. Safety Science, v. 24, pt. 3, p. 197-209, 1996.

RUTENFRANZ, J. Occupational health measures for night and shiftworkers. Journal of Human Ergology, v. 11, p. 67-86, 1982. Supplement.

SAMPAIO, J.; BORSOI, I.; RUIZ, E. Saúde mental e trabalho em petroleiros de plataforma: penosidade, rebeldia e conformismo em petroleiros de produção (onshore/offshore) no Ceará. Fortaleza: FLACSO/ EDUECE, 1998.

SCHLUMBERGER: tecnologia a serviço de um mundo melhor. TN Projetos Sociais - Revista Brasileira para Divulgação das Atividades de Responsabilidade Social no Setor de Óleo, Gás e Energia. Rio de Janeiro, ano 1, n. 1, p. 25-25, 2004.

SCHWARTZ, Y. De l'inconfort intellectuel, ou: comment penser les activités humaines?. In: COURS-SALIES, P. (Org.). La liberté du travail. Paris: Syllepse, 1995. p. 99-149.

. Le paradigme ergologique ou um métier de philosophe. Toulouse: Octarès Éditions, 2000.

SCHWARTZ, Y.; DURRIVE, L. (Org.) Trabalho \& Ergologia: conversas sobre a atividade humana. Tradução Milton Athayde e Jussara Brito. Niterói: EdUFF, 2007.

SELIGMANN-SILVA, E. Desgaste mental no trabalho dominado. Rio de Janeiro: Editora UFRJ/Cortez, 1994.

SEVÁ FILHO, A. "Seguuura, peão" - Alertas sobre o risco técnico coletivo crescente na indústria petrolífera 
(Brasil, anos 1990). In: MACHADO, J. M. H.; PORTO, M. S. F.; FREITAS, C. M., (Org.). Acidentes industriais ampliados: desafios e perspectivas para o controle e a prevenção. Rio de Janeiro: Editora Fiocruz, 2000. p. 169-196.

\section{SINDICATO DOS PETROLEIROS DO NORTE}

FLUMINENSE. Petroleiro sofre amputação em navio da Brasdril na Bacia. Boletim Nascente, Macaé, n. 624, p. 3, 28 out. 2009.

. Trabalhador da Brasdril perde a perna em acidente. Boletim Nascente, Macaé, n. 644, p. 3, 15 abr. 2010a.

. Contagem regressiva para mais uma tragédia na Bacia. Boletim Nascente, Macaé, n. 649, p. 2, 21 maio 2010b

SIQUEIRA, E.; NEUROHR, N. The sinking of the neoliberal P-36 plataform in Brazil. In: MOGENSEN, V. (Org.). Worker safety under siege: labor, capital, and the politics of workplace safety in a deregulated world. Armonk: ME Sharpe, 2005. p. 187-213.

SOUZA, C.; FREITAS, C. Perfil dos acidentes de trabalho em refinaria de petróleo. Revista de Saúde Pública, São Paulo, v. 36, n. 5, p. 576-583, 2002.

SUAREZ, J. Mobilização de competências na indústria petrolífera offshore: o caso da operação de lançamento de risers flexíveis na bacia de Campos (RJ). 2008. 124 f. Dissertação (Mestrado)-Escola de Engenharia,
Universidade Federal Fluminense, Niterói, RJ, Brasil, 2008.

SUTHERLAND, K. M.; FLIN, R. H. Stress at sea: A review of working conditions in the offshore oil and fishing industries. Work \& Stress, v. 3, n. 3, p. 269-285, 1989.

VERDIER, F.; BARTHE, B.; QUÉINNEC, Y. Organização do trabalho em turnos: concentrando-se na análise ergonômica ao longo das 24 horas. In: FISCHER, F; MORENO, C. R.; ROTENBERG, L. (Org.). Trabalho em turnos e noturno na sociedade 24 horas. São Paulo: Atheneu, 2003. p. 137-158.

WEDDERBURN, A. La Semaine de travail comprimée. Dublin: Foundation Europenne pour l'amelioration des conditions de vie et de travail, 1997.

WISNER, A. A inteligência no trabalho: textos selecionados de ergonomia. São Paulo: Fundacentro, 1994.

. Antropotechnologie: vers un monde industriel pluricentrique. Avec la collaboration de PAVARD, B.; BENCHEKROUN, T.; GESLIN, P. Toulouse: Octarès Éditions, 1997.

WOOLFSON, C. Paying for the piper: capital and labour in Britain's offshore oil industry. London: Mansell, 1996

WOOLFSON, C.; BECK, M. The British offshore oil industry after Piper Alpha. New Solutions, v. 10, n. 1-2, p. 11-65, 2000. 